\title{
Lean Implementation in Service Companies
}

\author{
Alberto Portioli-Staudacher \\ Politecnico di Milano \\ Department of Management, Economics and Industrial Engineering, \\ P.za Leonardo daVinci, 32 - 20133 Milano, Italy \\ alberto.portioli@polimi.it
}

\begin{abstract}
Service companies have been implementing Lean only in recent years. In this research three third party logistic companies and seven companies of the financial sector have been thoroughly interviewed and showed a few interesting aspects on the way they implemented Lean. They are implementing Lean in high volume low variety processes and focus on back office activities, which are most similar to manufacturing. Focus on flow, releasing real pull systems and attention to pacing the flow are the aspects that have been less developed and considered not applicable -or not worth applying- in services.
\end{abstract}

Keywords: lean services, service operations, banking, insurances, lean implementations.

\section{Introduction}

Focusing on the service sector has an outstanding importance, because of its increasing relevance on GDP of western economies: in the European Union, the percentage of employees in services was near $49 \%$ in 1971 and it became $68 \%$ in the late $1990 \mathrm{~s}$. In these nations the service sector contributes three times more to the GDP than the industry sector (Wolfl, 2005).

Nonetheless, referring to the labour productivity increase, it is evident services are lagging behind industry, especially in Europe. Increasing the productivity of the tertiary could give an impulse to the development of this sector and to the growth of the economy. Services represent the future source of growth for developed nations and it is in their best interest to understand the underlying causes of the low productivity growth (Druker, 1991). Despite operations is the area where most service people work -and the area where labour productivity increase can have the larger impact- there are still very few research works on service operations.

Adopting manufacturing proven management techniques, such as Lean Thinking, that had already helped the manufacturing sector improving its performances, service industries could improve their efficiency too. These would allow them to have more efficient and productive operations, and deliver better and more competitive services (Roach, 1998). However, Lean methodology can not be implemented in the same way in every situation: it needs to be tailored to the particular characteristics of each sector (Ahlstrom, 2004; Jones e Womack, 2005). 
The purpose of this paper is to investigate different contexts of application of the Lean methodology in the tertiary, in order to understand the differences in implementing Lean in services compared with manufacturing, and what are the typical ways of adopting it.

Which are the guidelines they follow, the objectives, the tools they use and the areas in which they preferably adopt the approach.

\section{Lean Implementation in Services}

Fist of all we started by interviewing about 600 service companies on the phone, to understand whether they were adopting Lean or, at least, implementing any Lean technique.

Out of the 600 companies contacted, less than $2 \%$ claimed they were adopting any Lean technique. Financial services (Banking and Insurances) are the ones where Lean is more known, and where an increasing number of companies are implementing Lean.

Healthcare organisations are starting to learn something about Lean, but implementations are rare; in tourism, rental, hotels and restaurants none of the companies contacted were implementing Lean.

Because Lean implementation in services has just started, it is important to understand how to make it successful. What to start from, and what possible similarities and differences there are from manufacturing. Therefore we decided to deepen the knowledge through structured interview in the few service companies that were implementing Lean. 10 companies agreed to participate to the research: 3 pertaining to third party logistics and 7 from the financial sector (banks and insurance companies).

Our research questions were the following:

1. What areas/processes are the first one to implement Lean?

2. What aspects of Lean are implemented? What others are more difficult to implement or left for the future?

\subsection{Processes}

Ahlstrom (2004) investigated four services:

- Street maintenance;

- Train maintenance;

- A School;

- A Hospital.

Ahlstrom identifies 7 aspect that characterise Lean: waste elimination, zero defects, pull rather than push, multifunctional teams, decentralised responsibilities, information flow, continuous improvement. 
Ahlstrom conclusions are that Lean is applicable in all 4 services, but he highlights differences in term of relevance of different aspects of Lean and difficulties for implementation.

Many other authors also agree that Lean principles are valid for both manufacturing and service companies but we believe that for a successful implementation it is important not to focus only on the differences among industries, but, most of all, on differences among processes (value streams in the Lean terminology). In fact, within the same industry there are companies competing on the base of very different processes, and different use of resources. For example, if we compare large Law Firms in Canada and in Italy, the offer of services is quite similar in range and variety, so it could seem that they should have a similar service delivery system. But if we take a closer look, we see that in Canada companies are structured with a more rigid allocation of resources to the different type of service offering, with a kind of sub systems with resources dedicated to a subset of services. Therefore each sub system has a narrower set of services to deliver. This means that if we take a look at this deeper level, resources in Canada handle a much lower variety and higher volumes than in the Italian Law Firms. The processes have quite a different structure.

In general, within a company there are low volume high variety processes, and high volume low variety processes. The management of these two types of processes is quite different.

In manufacturing, Lean started in the automotive industry and then spread to white goods and electronic appliances, i.e. to large volume production. Starting point for implementation is in virtually all cases the internal production process, from raw material to finished products. Then implementation spreads to the external production process, going upstream to suppliers and downstream to distributors. Implementing Lean to administrative processes and new product development it is usually the last stage (Portioli and Tantardini 2007). Therefore we expect a similar trend in Services also, where we expect that companies start from high volume processes.

Moreover services have large differences from manufacturing, and most operations management books start the chapter on service operations with a list of key element differentiation services from products: they are intangible, perishable, etc. But in our opinion the most important single difference in Operations between services and manufacturing is the presence of the customer in the service delivery system.

The interaction with the customer brings an element that is totally new to manufacturing operations.

Therefore we expect that service companies start implementing Lean on processes that are high volume low variety, and focused on back office, where there is not the new element of the customer presence.

Table 1 presents the results of the research, showing the characteristics of the processes involved in the Lean transformation for all companies analysed. Certain companies changed more than one process, but all processes showed the same characteristics, therefore they have been grouped in one single column for each company.

All companies interviewed but one implemented Lean in high volume processes. Company B implemented Lean in process with a medium low volume compared with the other companies, but it is still one of the processes with the highest volume among the ones within the company. 
Table 1. Characteristics of the processes affected by the Lean implementation

\begin{tabular}{|c|c|c|c|c|c|c|c|c|c|c|c|}
\hline \multirow{3}{*}{$\begin{array}{c}\text { Process } \\
\text { characteristics }\end{array}$} & & \multicolumn{10}{|c|}{ Company } \\
\hline & & \multicolumn{3}{|c|}{$\begin{array}{l}\text { Warehousing } \\
\text { and Shipping }\end{array}$} & \multicolumn{7}{|c|}{ Financial services } \\
\hline & & $\mathrm{H}$ & I & $\mathrm{L}$ & A & $\mathrm{C}$ & B & E & $\mathrm{F}$ & D & G \\
\hline \multirow[t]{2}{*}{ Volume } & High & $\sqrt{ }$ & $\sqrt{ }$ & $\sqrt{ }$ & $\sqrt{ }$ & $\sqrt{ }$ & $\sqrt{ }$ & $\sqrt{ }$ & $\sqrt{ }$ & $\sqrt{ }$ & $\sqrt{ }$ \\
\hline & Low & & & & & & $\sqrt{ }$ & & & & \\
\hline & & & & & & & & & & & \\
\hline \multirow[t]{2}{*}{ Variety } & High & & & & & & $\sqrt{ }$ & & & & \\
\hline & Low & $\sqrt{ }$ & $\sqrt{ }$ & $\sqrt{ }$ & $\sqrt{ }$ & $\sqrt{ }$ & & $\sqrt{ }$ & $\sqrt{ }$ & $\sqrt{ }$ & $\sqrt{ }$ \\
\hline \multirow{2}{*}{ Process focus } & Front Office & & & & & & $\sqrt{ }$ & & & & \\
\hline & Back Office & $\sqrt{ }$ & $\sqrt{ }$ & $\sqrt{ }$ & $\sqrt{ }$ & $\sqrt{ }$ & $\sqrt{ }$ & $\sqrt{ }$ & $\sqrt{ }$ & $\sqrt{ }$ & $\sqrt{ }$ \\
\hline & & & & & & & & & & & \\
\hline \multirow{2}{*}{$\begin{array}{l}\text { Operators' } \\
\text { discretion }\end{array}$} & High & & & & & & $\sqrt{ }$ & & & & \\
\hline & Low & $\sqrt{ }$ & $\sqrt{ }$ & $\sqrt{ }$ & $\sqrt{ }$ & $\sqrt{ }$ & & $\sqrt{ }$ & $\sqrt{ }$ & $\sqrt{ }$ & $\sqrt{ }$ \\
\hline \multirow[t]{2}{*}{ Customisation } & High & & & & & & $\sqrt{ }$ & & & & \\
\hline & Low & $\sqrt{ }$ & $\sqrt{ }$ & $\sqrt{ }$ & $\sqrt{ }$ & $\sqrt{ }$ & & $\sqrt{ }$ & $\sqrt{ }$ & $\sqrt{ }$ & $\sqrt{ }$ \\
\hline & & & & & & & & & & & \\
\hline
\end{tabular}

Similarly, variety in those processes is low, except for company B where the process shows a higher variety.

The difference is due to the fact that B is a corporate bank, while the others are retail banks and insurances. Therefore overall volume of transactions in B is much smaller.

All companies have selected back office processes for implementing lean, with the only exception of $\mathrm{B}$ that worked also on a process mainly focused on back office but that has also a part in front office.

The processes under consideration involve operators with a low degree of discretion, B presents operators with a higher degree of discretion compared with the other companies, but most of the operators involved in B do not have a higher degree of discretion than the average in the company

The processes involved allow a low degree of customisation for all companies, except for B.

The results presented in Table 1 confirm that service companies start implementing lean in processes with higher volume and lower variety. This is mainly due to the following reasons:

- Changing a high volume process usually affects a larger portion of the business, therefore with one intervention there is a benefit on a significant portion of the output.

- It is easier to find a sponsor when the benefits expected are large (due to large volume)

- Low variety makes it easier to understand the process and to make changes

In particular, variety is a critical aspect in services: all employee think that all customer requests are different from one another, and have to be addressed 
specifically. "Every customer has specific needs and specific situations, and we have to satisfy it. Out job is not like producing iron pieces!"

This is true if we passively ask the customers to tell us what they want and then try to satisfy it; but not all differences have the same relevance. In many cases, most differences have no real value for the customer, and can be easily eliminated by a better customer management. But in order to achieve this it is important to make the employee understand on the one hand that customers can be directed, and in many cases they like to be directed by someone who knows their needs and how to satisfy them. On the other hand, the huge impact that a reduction in variety and variability has on productivity. This leads to lower costs -lower prices for the customers- and shorter response time. The front office should handle all the variety from the customer, and funnel it into the few standard alternatives that the service provider has designed. In the back office there should not be other than standard requests. If there are customers with really exceptional needs, they should be directed to a different process that addresses high variety low volume, non standard customers. Or they should be rejected.

In other words, front office has to manage variety and variability, because it is due to the customer. A new element compared with manufacturing. On the contrary, back office should reduce variety and variability, as in manufacturing.

Almost all lean implementation considered, addressed back office processes only, and processes where little or no customisation were allowed.

\subsection{Lean Elements}

The second research question is related with what Lean aspects are implemented, and how.

In order to understand this, we defined nine elements: seven are based on the one defined by Ahlstrom, even though in certain cases with a deeper meaning, two have been added.

For each element we also defined a level of implementation, so to highlight how far the company has gone in adopting it in line with the Lean approach.

For example, as for pull rather than push, most service companies start from a customer order, therefore the company as a whole is acting on a pull base, but this does not mean that pull is preserved along the delivery system (through the value stream). Let's consider the mortgage granting process: all starts with a request from the customer, it is pulled by the customer, but this does not mean that there is pull between each stage. Usually, each stage is asked to process the requests as fast as possible: result is that there is a large variation in the response time to the customer. An analysis of the different mortgage requests at a bank highlighted an average response time of 15 days, but certain customer got the answer in 5 days and others took as long as 30 . The first reaction was to think that response time was linked to the amount requested, but a segmentation with different amounts requested gave no evidence in this direction. The answer is that there was no pull in place between stages and each stage processed requests so to optimise its own performances, with no view on overall. End to end, process. 
A better pull solution is to set a service level at each stage -say $90 \%$ of requests processed within 3 days- so to avoid that requests remain at a single stage for too long.

The full pull solution is a sequential pull, with FIFO line between stages. Each stage processes the requests in the same order that they have arrived from the upstream stage and the queue at each stage has a maximum number of request that it can hold: when the queue is full the stage upstream cannot process any more request till the stage downstream does pick up a request from the queue, and frees up a place. This reduces dramatically variations in response time and sets up a clear system that highlights any problem as soon as it arises. If the maximum is reached it is a signal that there in an unbalance between the two stages. Similarly when the queue is empty. Zero defects has as a basic level the recording of defects and targets on their maximum levels, and as an advanced level a system that systematically analyses defects to find the root cause in order to solve it, and set ups pokayoke devices to prevent errors from happening.

Pace. Basic element is to use the takt time to have a target for the daily, or weekly, output. The target level is to have a system that gives the operators a sense of the pace, help them to keep up with it and triggers an alert when pace is not met: not for blaming anybody, but for spotting improvement opportunities.

Flow is a key aspect for lean, and we analysed which company exploited it till the level of having the flow as the central point for the allocation of resources, the organisation, and even the layout. A basic level is to identify a flow of the service required and have an overall view and understanding, from beginning to end. Many companies did this in conjunction with the process mapping activity required by quality certification. But the target level is to dedicate resources to the flow, to manage the flow as a whole, to review the layout to support the flow. IT systems and procedure design is also considered in this direction, looking for systems that are designed to support the flow, not the single stage.

Finally, continuous improvement is at a basic level the tension to improve results, but the target level is to have the operators to proactively, and on a continuative base, present, select, implement improvements.

Table 2 shows the results of the research on Lean elements: third party logistics is ahead of financial services on almost all items, despite these companies did not start before the others. The key point seems to be the presence of a physical item, with simple operations (no transformation and little assembly, if any). Storing and moving something are operations that have been performed massively by manufacturing companies and addressed by Lean researchers and practitioners, unlike operations in banks and insurance companies, where activities are mostly related to information processing.

There are differences in the degree of implementation in the different companies but there are some common elements:

- Waste elimination is pursued in all companies, but what is missing is to have this attitude disseminated among all operators, making waste elimination a continuous process in all the company;

- Multifunctional teams are common practice but they are used on a project base rather than a continuative base 
- Continuous improvement is intended more as spreading practices to the other part of the company/group performing the same process, or to other similar processes rather than setting up a system that continuously improve a process.

The dominant culture in the companies interviewed is to set up a multifunctional team, give it a process and a target, achieve results (new practice), and spread to other part of the company. Rather than setting up a system based on operators, that continuously reduce waste, find improvement opportunities and realise them.

Table 2. Degree of implementation of key elements of Lean on a 0-4 scale

\begin{tabular}{|l|l|l|l|l|l|l|l|l|l|l|}
\hline \multirow{3}{*}{ Process characteristics } & \multicolumn{9}{|c|}{ Company } \\
\cline { 2 - 13 } & $\begin{array}{l}\text { Warehousing } \\
\text { and Shipping }\end{array}$ & \multicolumn{7}{|c|}{ Financial services } \\
\cline { 2 - 13 } & H & I & L & A & C & B & E & F & D & G \\
\hline Waste elimination & 4 & 4 & 4 & 4 & 4 & 2 & 2 & 2 & 2 & 2 \\
\hline Zero defects & 2 & 4 & 0 & 2 & 2 & 2 & 2 & 2 & 2 & 0 \\
\hline Multi functional teams & 2 & 4 & 2 & 4 & 2 & 2 & 2 & 2 & 2 & 2 \\
\hline Decentr. responsibilities & 0 & 4 & 2 & 0 & 4 & 2 & 2 & 2 & 2 & 2 \\
\hline Information flow & 4 & 4 & 2 & 0 & 2 & 2 & 2 & 2 & 2 & 2 \\
\hline Continuous improvement & 2 & 4 & 2 & 0 & 2 & 2 & 2 & 2 & 2 & 0 \\
\hline Pull & 2 & 2 & 2 & 2 & 2 & 3 & 1 & 1 & 1 & 2 \\
\hline Pace & 0 & 3 & 3 & 2 & 3 & 2 & 1 & 2 & 1 & 1 \\
\hline Flow & 3 & 3 & 2 & 2 & 3 & 2 & 1 & 2 & 2 & 2 \\
\hline
\end{tabular}

Pull, Pace and Flow are at an intermediate level of development, but companies are not striving to improve them very much. The dominant feeling is that in services it is not possible -or it is not worth- develop them further.

Therefore, there are no FIFO line with limited capacity between stages, takt time is used only to set target output per day or week, and flow is not affecting layout, nor organisation, nor IT system design and development.

\section{Conclusions}

Services are different from manufacturing and Lean implementation has just started. This research identified two key elements in Lean implementation: the need to address the issue at a single process level, highlighting the fact that service companies start from high volume, low variety processes, which are focused on the back office. This to avoid the criticality customer interaction, which is not present in manufacturing operations and has therefore not been addressed before.

Nine key elements of Lean have been defined and their degree of implementation investigated. Results shows that third party logistic companies, that process a physical product, are more advanced in Lean implementation than banks and insurance companies (financial services). These latter types of companies are lagging behind manufacturing in particular in implementing a sequential pull system between stages, in putting the flow at the center of operation's organisation, layout and IT systems, 
and in considering Pace as a key tool for highlighting deviations and therefore improvement opportunities.

The feeling emerged from the people interviewed is that these elements are not possible to implement, or not key, in services.

Improvement achieved so far are so interesting that they are focusing on spreading the new practices to other part of the company/group, rather than seeking to achieve further improvements in the process already tackled through Lean.

Finally, the improvement approach is still based on the idea of improvement projects with a multifunctional project team, a start and an end, rather than working for setting up a system, based on operators, that continuously seek opportunities to improve, find solutions and implement them.

\section{References}

1. Ahlstrom, P.: Lean service Operation: translating lean production principles to service operations. International Journal of Services Technology and Management 5(5/6), 545-564 (2004)

2. Drucker, P.F.: The new productivity challenge. Harvard Business Review 69(6), 69-79 (1991)

3. Portioli, A., Tantardini, M.: Lean production implementation: a survey in Italy. In: International conference on Industrial engineering and Industrial Management, Madrid, September 5-7 (2007)

4. Roach, S.S.: In Search of Productivity. Harvard Business Review, 158 (September-October 1998)

5. Wölfl, A.: The service Economy in OECD Countries. STI Working Paper Series, 2005/3. OECD (2005)

6. Womack, J.P., Jones, D.: Lean Consumption. Harvard Business Review (2005) 